\title{
ALTERNATIVAS AL ENCARCELAMIENTO DE LA PERSONA A CARGO DE MENORES SOMETIDAA UN PROCESO PENAL*
}

\author{
Carmen Navarro Villanueva**
}

\begin{abstract}
Resumen: Los efectos que el encarcelamiento de la persona encargada del cuidado de menores, y, en especial, de la madre, causa en aquellos suelen ser devastadores. Por esa razón, es preciso abogar por un sistema de justicia penal que garantice el respeto y la efectiva implementación de todos los derechos del niño. A tal fin, se hace necesario introducir en el penal aquellas medidas que puedan, al menos, minimizar los perniciosos efectos que la prisión del cuidador pueda ocasionar. Consecuentemente, a partir de la normativa vigente en España y de diversas propuestas de lege ferenda, este trabajo analizará las medidas que se podrían adoptar desde el inicio del proceso penal contra el cuidador principal hasta el cumplimiento, en su caso, de la pena impuesta de la manera más acorde a los intereses de los menores a su cargo.
\end{abstract}

* Este trabajo se inserta en el Proyecto "Familia: desistimiento y reincidencia", concedido por el Ministerio de Ciencia, Innovación y Universidades del Gobierno de España, iniciado el 1. ${ }^{\circ}$ de enero de 2019 y que finalizará el 31 de diciembre de 2021 (referencia: RT2018-097085-B-100). El tema analizado fue objeto de análisis en mi monografía El encarcelamiento femenino. Especial consideración a las madres privadas de libertad, publicado por la editorial Atelier, Barcelona, en 2018.

Profesora titular de Derecho Procesal en la Universidad Autónoma de Barcelona-Bellaterra. Correo-e: maricarmen.navarro@uab.cat. Fecha de recepción: 11 de enero de 2020. Fecha de aceptación: 12 de enero de 2021. Para citar el artículo: Carmen NaVArro Villanueva. "Alternativas al encarcelamiento de la persona a cargo de menores sometida a un proceso penal", Revista Derecho Penal y Criminología, vol. 41, n. ${ }^{\circ}$ 110, enero-junio de 2020, Bogotá, Universidad Externado de Colombia, pp. 57-89. DOI: https://doi.org/10.18601/ 01210483.v41n110.04. 
Palabras clave: menores; maternidad; encarcelamiento; alternativas a la prisión; interés superior del menor.

\title{
ALTERNATIVES TO THE IMPRISONMENT OF THE MAIN CARETAKER OF CHILDREN SUBJECTED TO A CRIMINAL PROCEEDINGS
}

\begin{abstract}
The effects that the imprisonment of the children's main caretaker, especially if their mother is incarcerated, are usually devastating. However, we must ensure a justice system which guarantees the respect and the effective implementation of all children's rights. Therefore, it becomes necessary to introduce in our Criminal justice system all the measures that can, at least, minimise the harmful effects that the imprisonment of the mother may cause on children. Consequently, this paper analyses, taking into account the Spanish legislation, the potential measures to be taken against the mother or the primary caregiver of a child, from the beginning of the Criminal proceedings to, if necessary, the enforcement of the sentence.
\end{abstract}

Keywords: children; motherhood; imprisonment; alternatives to prison; best interest of the child.

\section{CONSIDERACIONES PREVIAS}

El objetivo principal de este estudio será mostrar, a partir de la normativa española, algunas de las alternativas al encarcelamiento que pueden reducir el número de personas privadas de libertad que, con carácter previo a su eventual ingreso en prisión, estaban a cargo de menores de edad. Tales personas serán, por lo general, las madres, dado que cuando el progenitor encarcelado es el padre, el hijo suele seguir viviendo con la madre. Sin embargo, si es la madre la privada de libertad, tal situación provocará, las más de las veces, que esos niños no van a poder seguir viviendo en su casa y tendrán que cambiar de cuidador y mudarse, en ocasiones, de ciudad y, por ende, de escuela ${ }^{1}$.

Diversas razones nos llevan a abogar por un tratamiento diferenciado de los cuidadores principales de menores de edad que han de enfrentarse a un proceso penal que puede concluir con la imposición de una pena de prisión. En efecto, la justificación

1 Así, tras el análisis pormenorizado de los datos relativos a los hijos de las mujeres encarceladas en prisiones de Cataluña en 2015, se constató que los niños permanecieron, en la mayoría de los casos con los abuelos $(48,96 \%)$ y, en mayor proporción, con los abuelos maternos $(70,3 \%)$ que con los paternos $(29,7 \%)$, pese a los problemas de salud o de otro tipo que, a resultas de la edad, puedan padecer estas personas. Vid., más ampliamente, Navarro Villanueva, El encarcelamiento femenino. Especial consideración a las madres privadas de libertad, Atelier, Barcelona, 2018, pp. 88 y ss. 
de ese diverso tratamiento deriva, por una parte, de la necesidad de tener en cuenta también en la política criminal el interés superior del menor en cualquier decisión que pueda suponer una devaluación de sus derechos, que siguen siendo los mismos que los de cualquier otro niño ${ }^{2}$.

Por otra parte, los efectos que el encarcelamiento de un progenitor o del principal cuidador provoca en los niños pueden llegar a ser altamente perniciosos a corto y a largo plazo. Tales efectos van desde: (a) la interrupción de los lazos paterno-filiales, que se verá agravada en aquellos casos en que no haya visitas; el consiguiente debilitamiento del rol maternal o paternal, debido a la separación, provocará dificultades para reconstruir tales relaciones una vez producida la excarcelación; (b) agudos problemas financieros que dificultarán, entre otras cuestiones, las visitas; piénsese, además, que en muchos supuestos ya se parte de una situación familiar económica inestable y difícil con anterioridad al encarcelamiento del progenitor; (c) estigmatización y aislamiento social, amén de discriminación y soledad, ya que los hijos de personas encarceladas suelen sentirse marginados y socialmente excluidos por sus compañeros y en la propia comunidad; (d) problemas de salud y de comportamiento en los niños, que difieren dependiendo de si el progenitor encarcelado es el padre o la madre o (e) mayor probabilidad de delinquir y de entrar en el sistema de justicia juvenil y, por ende, después en el de adultos, por citar algunos ${ }^{3}$.

Con el fin de poner de presente los negativos efectos que la puesta en marcha del sistema de justicia penal puede causar en los niños, es necesario abogar por las reformas que tengan en cuenta los derechos de los niños y el interés superior del menor. Se trata, en definitiva, de minimizar los efectos que el impacto de la justicia

2 Entre los principios rectores de la política social y económica, la Constitución española destaca la protección social, económica y jurídica de la familia (art. 39.1) y dentro de ésta, la protección integral de los hijos (arts. 39.2 y 3). Por su parte, el artículo 39.4 de la Carta Magna establece que los niños gozarán de la protección prevista en los acuerdos internacionales que velan por sus derechos y, en consecuencia, tratándose de niños de padres encarcelados en España, les serán de aplicación, por citar algunos de esos acuerdos, la Declaración de la Asamblea General de las Naciones Unidas sobre Derechos del niño (2009), las conocidas Reglas de Mandela o Normas Mínimas de Naciones Unidas para el tratamiento de los reclusos de 2015 o las Reglas de las Naciones Unidas para el tratamiento de las reclusas y medidas no privativas de libertad para las mujeres delincuentes (Reglas de Bangkok) de 2011, entre otros.

3 La doctrina anglosajona, especialmente, se ha ocupado de estudiar los efectos que el encarcelamiento de los padres tiene en los hijos. Vid., entre otros, Murray Joseph y Farrington David, "The effects of parental imprisonment on children", en Tonry (ed.), Crime and Justice: A review of research, vol. 37 , pp. 133 a 206, Chicago, IL: University of Chicago Press; Crawford Jackie, "Alternative sentencing necessary for female inmates with children", en Corrections today, junio 2003, n. ${ }^{\circ}$ 65, t. 3 , pp. 8 a 10 ; Convery Una y Moore Linda, "Children of imprisoned parents and their problems", en Scharff-Smith Peter y Gampell Lucy (eds.), Children of imprisoned parents; Reed Kristiina, "Children of prisoners: 'orphans of justice'?", en Fam Law, January, 2014; Robertson Oliver, El impacto que el encarcelamiento de un(a) progenitor(a) tiene sobre sus hijos, Quaker ONU, abril, 2007; Marshall Kathleen, Not seen, not heard, not guilty, the rights and status of the children of prisoners in Scotland, 2008. 
criminal puede ocasionarles y por ello, la protección integral al menor deberá tenerse en cuenta desde la incoación del proceso penal contra su cuidador principal hasta, en su caso, el momento del cumplimiento definitivo de la condena por aquél. De este modo, en el presente trabajo se intentará realizar un recorrido por las distintas fases del proceso penal contra el progenitor o cuidador principal con el propósito de destacar, respecto de cada una de ellas, las medidas más acordes con los derechos de los niños a su cargo.

\section{ALTERNATIVAS AL ENCARCELAMIENTO CON CARÁCTER PREVIO AL JUICIO}

La Ley de Enjuiciamiento Criminal española (LECrim, en adelante) prevé en su artículo 502.2 que la prisión provisional "sólo se adoptará cuando objetivamente sea necesaria, de conformidad con lo establecido en los artículos siguientes y cuando no existan otras medidas menos gravosas para el derecho a la libertad a través de las cuales puedan alcanzarse los mismos fines que con la prisión provisional"4.

Por su parte, el artículo 503 LECrim recoge los presupuestos que deben concurrir para la adopción de esta medida cautelar, con carácter previo al juicio y que, resumidamente, son los siguientes:

1. . Existencia de uno o varios hechos que presenten caracteres de delito sancionado con pena cuyo máximo sea igual o superior a dos años de prisión o bien con una pena privativa de libertad de duración inferior si el investigado o encausado tuviera antecedentes penales no cancelados ni susceptibles de cancelación, derivados de condena por delito doloso.

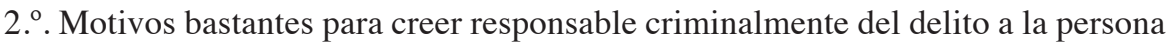
contra quien se haya de dictar el auto de prisión.

3. . . Concurrencia de alguno de las siguientes finalidades: (a) asegurar la presencia del investigado o encausado en el proceso cuando pueda inferirse racionalmente un riesgo de fuga; (b) evitar la ocultación, alteración o destrucción de las fuentes de prueba relevantes para el enjuiciamiento en los casos en que exista un peligro fundado y concreto; (c) evitar que el investigado o encausado pueda actuar contra bienes jurídicos de la víctima, especialmente cuando ésta sea alguna de las personas a las que se refiere el artículo $173.2 \mathrm{CP}$ (cónyuge o persona con la que haya o

4 Y, sin embargo, el 22,8\% de las madres que en 2015 se encontraban en algún centro penitenciario catalán lo estaban con carácter de preventivas. Entre todas ellas, sumaban un total de 479 hijos, cifra tan elevada que obliga a buscar alguna solución para evitar el encarcelamiento de aquellas madres que, sin duda alguna, de acuerdo con la garantía procesal de presunción de inocencia, son todavía inocentes. 
haya habido relación de afectividad, descendientes, ascendientes, hermanos...) y (d) evitar el riesgo de que el investigado o encausado cometa otros hechos delictivos.

Ahora bien: aun tratándose de un delito castigado con más de dos años prisión o pese a que concurra cualesquiera de los presupuestos reproducidos en el párrafo anterior, debe tenerse presente el carácter excepcional de la medida cautelar, de manera que, de acuerdo con lo previsto en el artículo 502.2 LECrim, podrá acordarse "sólo cuando objetivamente sea necesaria [...] y no existan otras medidas menos gravosas para el derecho a la libertad". En esta misma línea, además, el juez tendrá que tener en cuenta para adoptar la prisión provisional, según se infiere de lo dispuesto en el artículo 502.3 LECrim, "la repercusión que esta medida pueda tener en el investigado o encausado, considerando sus circunstancias y las del hecho objeto de las actuaciones, así como la entidad de la pena que pueda ser impuesta”. Esto es, el juez ha de tener en cuenta al decretar la prisión provisional, amén de los presupuestos señalados, la "repercusión" que tal medida puede suponer a la persona contra la que se acuerde. Por tanto, aferrándonos a tal precepto, encarcelar de manera preventiva a una madre o, en general, a la persona que se encuentra al cuidado de unos menores debe revestir más si cabe, una medida de carácter excepcional, y ello porque, además, la reproducida disposición obliga al órgano judicial a tener en consideración las "circunstancias" que rodean al encausado o investigado. Cierto es que el legislador no menciona ni explicita qué circunstancias han de ser consideradas, pero las cargas familiares son, sin duda, un factor que puede inclinar la balanza definitivamente a favor de la libertad de la persona que aún no ha sido juzgada para que ésta pueda continuar al cuidado de los hijos o, en su caso, de los menores que tiene a su cargo.

Llama la atención que, como señalé, nuestra legislación procesal no tiene en cuenta, de manera explícita, los intereses del menor al valorar la idoneidad de una medida cautelar. Paradójicamente, sí se tienen en cuenta las circunstancias familiares cuando se trata de valorar el riesgo de fuga de la persona que puede ser sometida a prisión provisional. Por otro lado, como se ha afirmado, el artículo 502.3 LECrim hace alusión a la repercusión de la medida en el encausado pero no en su familia. A mi juicio, si el encausado/a es el principal cuidador de unos niños que pueden quedar en peor situación a resultas del encarcelamiento, habría que plantearse de lege ferenda la introducción de un nuevo supuesto de prisión preventiva privilegiada "por cargas familiares", que permitiera a la madre, al padre o al cuidador principal si no es ninguno de los progenitores permanecer en el domicilio familiar a la espera de la celebración del juicio sin tener que ingresar en prisión de manera provisional (art. 508 LECrim) ${ }^{5}$.

5 El artículo 508 LECrim prevé dos supuestos de "prisión preventiva atenuada" en los que la persona investigada o encausada puede permanecer en su domicilio, con las medidas de vigilancia que resulten necesarias o en un centro para su deshabituación: (1) por enfermedad siempre que el internamiento entrañe grave peligro para su salud (508.1 LECrim); (2) por seguir el investigado/encausado un tratamiento de desintoxicación o deshabituación a sustancias estupefacientes si el ingreso en prisión pudiera frustrar el resultado de dicho tratamiento (art. 508.2 LECrim). 
Para concluir, conviene traer a colación lo dispuesto en las Reglas de las Naciones Unidas para el tratamiento de las reclusas y medidas no privativas de libertad para las mujeres delincuentes (Reglas de Bangkok): "Antes de su ingreso o en el momento de producirse, se deberá permitir a las mujeres con niños a su cargo adoptar disposiciones respecto de ellos, previéndose incluso la posibilidad de suspender la reclusión por un período razonable, en función del interés superior de los menores" (regla 2.2).

\section{ALTERNATIVAS A LA PRISIÓN TRAS LA CONDENA A UNA PENA PRIVATIVA DE LIBERTAD}

Toca ahora ocuparnos de las alternativas para eludir el encarcelamiento en el caso de condena del principal cuidador de menores que se reducen hoy en día, al menos en España, a la suspensión condicional de la ejecución de la pena en los términos que seguidamente veremos.

\subsection{La suspensión condicional ordinaria: concepto, fundamento y requisitos para su concesión}

La suspensión condicional de la pena consiste en excluir provisionalmente el cumplimiento de la pena privativa de libertad impuesta en sentencia firme a la persona autora de un delito menos grave, si el juez o tribunal sentenciador considera que no es probable que dicha persona vuelva a cometer nuevos delitos. De este modo, la pena se sustituye por la amenaza de llevarse a efecto si se incumplen, durante un determinado plazo de tiempo, las condiciones bajo las cuales se acuerda la suspensión. En consecuencia, si la persona condenada cumple las condiciones impuestas durante el plazo fijado, se remite definitivamente la pena, dándose esta por cumplida. Por el contrario, en caso de incumplimiento de las condiciones impuestas se revoca la suspensión y se ordena el cumplimiento de la pena.

La fundamentación básica de esta institución radica en evitar la entrada en prisión de personas que han cometido un delito de escasa gravedad, por el efecto contrario a la reeducación y a la reinserción social que ésta podría comportar.

La suspensión de la ejecución de la pena está sometida a unas condiciones que podríamos denominar objetivas, recogidas en el reformado artículo 80.2 del Código Penal español (CP, en adelante): (1. $\left.{ }^{a}\right)$ delincuente "primerizo" en los términos descritos en el precepto citado ${ }^{6} ;\left(2 .^{a}\right)$ pena no superior a los dos años; $\left(3 .^{a}\right)$ satisfacción de la responsabilidad civil y del decomiso acordado en sentencia ${ }^{7}$, en su caso.

6 A efectos de valorar el carácter primerizo de la persona condenada, el artículo 80.2, 1 CP dispone que "no se tendrán en cuenta las anteriores condenas por delitos imprudentes o por delitos leves, ni los antecedentes penales que hayan sido cancelados, o debieran serlo con arreglo a lo dispuesto en el artículo 136. Tampoco se tendrán en cuenta los antecedentes penales correspondientes a delitos que, 
Ahora bien: aun concurriendo tales condiciones, la concesión del beneficio no es automática, ya que el criterio básico que ha de tener en cuenta el juez o tribunal que se plantee la posibilidad de suspender la ejecución de la pena será que "sea razonable esperar que la ejecución de la pena no sea necesaria para evitar la comisión futura por el penado de nuevos delitos". A tal efecto, deberá valorar los parámetros: las circunstancias del delito cometido y de su autor, los antecedentes de éste último y su conducta (en particular, su esfuerzo de reparación), las circunstancias familiares y sociales así como los efectos que quepa esperar de la suspensión y del cumplimiento de las medidas impuestas.

En definitiva, de acuerdo con la regulación de esta medida alternativa a la prisión, la suspensión de la condena impuesta al progenitor o cuidador principal sin antecedentes penales sólo será posible en caso que haya sido condenado por la comisión de un delito relativamente "leve", dado que la pena a suspender o la suma de las penas impuestas no puede ser superior a dos años, sin incluir en tal cómputo la derivada del impago de multa (art. 80. 2.2 $2^{\mathrm{a}} \mathrm{CP}$ ). Tal requisito excluye, prácticamente de manera automática, a todas aquellas personas condenadas por delitos contra la salud pública y, en algunos casos dependiendo de las circunstancias que rodearon la comisión del delito, también de aquéllas condenadas por delitos contra el patrimonio que son los principales delitos cometidos en España tanto por hombres como por mujeres ${ }^{8}$.

\subsubsection{Las modalidades "especiales” de suspensión condicional}

Junto a la modalidad descrita en el párrafo anterior que podríamos denominar "ordinaria", el legislador español contempla, en el mismo artículo $80 \mathrm{CP}$, sendas modalidades especiales y una tercera que sería un supuesto similar a la antigua sustitución, derogada por la reforma del CP de 2015:

1. La suspensión de la ejecución a penados aquejados de enfermedad muy grave con padecimientos incurables, siempre que no tengan una pena ya suspendida por este motivo (art. $80.4 \mathrm{CP}$ ).

2. $\quad$ La suspensión de la ejecución a condenados a penas inferiores a cinco años de prisión que hubieran cometido el delito a consecuencia de su dependencia a

por su naturaleza o circunstancias, carezcan de relevancia para valorar la probabilidad de comisión de delitos futuros".

7 En cuanto a este último requisito el citado artículo 80.2 CP in fine señala que se entenderá cumplido "cuando el penado asuma el compromiso de satisfacer las responsabilidades civiles de acuerdo a su capacidad económica y de facilitar el decomiso acordado, y sea razonable esperar que el mismo será cumplido en el plazo prudencial que el juez o tribunal determine". Así mismo, autoriza al órgano judicial que ha de acordar, en su caso, la suspensión, a solicitar las garantías convenientes para asegurar el cumplimiento del requisito analizado "en atención al alcance de la responsabilidad civil y al impacto social del delito".

8 Vid., más ampliamente, Navarro Villanueva, El encarcelamiento femenino, cit., pp. 54 a 61. 
determinadas sustancias y que deberán someterse a tratamiento de deshabituación (art. 80.5 CP); y

3. La suspensión de la ejecución de penas de prisión al penado no primerizo que tampoco es "habitual" condenado a penas que individualmente no excedan de dos años de prisión. Esta suspensión queda condicionada a la reparación efectiva del daño o a la indemnización del perjuicio o al cumplimiento del acuerdo de mediación. De todos modos, es éste un claro supuesto de sustitución del título ejecutivo dado que "se impondrá siempre una de las medidas a que se refieren los numerales 2 o 3 del mismo precepto, con una extensión que no podrá ser inferior a la que resulte de aplicar los criterios de conversión fijados en el mismo sobre un quinto de la pena impuesta" (art. 80.3 CP).

Cualquiera de las modalidades "especiales” de suspensión sería aplicable al progenitor o principal cuidador y, en especial, la prevista en aquellos casos de dependencia a sustancias tóxicas y el supuesto de sustitución.

Por lo que respecta a la suspensión para personas que hayan delinquido a causa de su dependencia de las sustancias señaladas en el numeral 2 del artículo $20 \mathrm{CP}$, cabe recordar, por una parte, el elevado número de personas usuarias de drogas que han de afrontar un proceso penal y, por otra, que en tales casos se eleva a cinco años la condena a suspender ${ }^{9}$. De este modo, resulta patente que estamos ante una alternativa que podría beneficiar a muchos de los progenitores o cuidadores principales encarcelados y que, además, podría ayudar a resolver la adicción y a evitar la reincidencia. Así, será requisito para acordar esta modalidad que "se certifique suficientemente, por centro o servicio público o privado debidamente acreditado u homologado, que el condenado se encuentra deshabituado o sometido a tratamiento para tal fin en el momento de decidir sobre la suspensión" (art. 80.5 CP). Por tanto, estamos ante dos escenarios posibles: (a) que el progenitor o cuidador principal ya haya superado su adicción al tiempo de acordar la suspensión y (b) que no la haya superado pero se encuentre en tratamiento.

Del nuevo supuesto regulado en el artículo $80.3 \mathrm{CP}$, esto es, de la sustitución, me ocuparé en el siguiente epígrafe.

\subsubsection{Requisitos para el mantenimiento de la suspensión de la ejecución hasta la remisión de la pena}

El plazo de suspensión que podrá imponerse al condenado que quiera ver remitida su pena es el de dos a cinco años para las penas privativas de libertad no superiores a dos años (de tres a cinco para la modalidad de suspensión del apartado quinto del

9 Vid., de nuevo, Navarro Villanueva Carmen, El encarcelamiento femenino, cit., pp. 47 a 49. 
artículo $80 \mathrm{CP}$ ) y de tres meses a un año para las penas leves. Dicho plazo se computará desde la fecha de la resolución que la acuerda. En este sentido, el artículo 82.2 CP aclara que si la suspensión hubiera sido acordada en la sentencia, deberá tomarse como dies a quo del plazo de suspensión, la fecha en que la sentencia ha devenido firme.

La suspensión de la ejecución de la pena está supeditada, con arreglo a lo previsto en el artículo $86 \mathrm{CP}$, a la observancia de determinados deberes y condiciones.

La primera de las condiciones que debe cumplir la persona a la que se ha otorgado el beneficio de la suspensión es la de no delinquir durante el plazo de suspensión o de prueba fijado por el juez o tribunal sentenciador. En este sentido, el mencionado precepto establece que se revocará la suspensión cuando el beneficiario de la medida "sea condenado por un delito cometido durante el período de suspensión y ello ponga de manifiesto que la expectativa en la que se fundaba la decisión de suspensión adoptada ya no puede ser mantenida". Se trata, además, de una condición común a toda pena suspendida, a diferencia, por ejemplo, de las reglas de conducta que podrán imponerse potestativamente por el órgano judicial "cuando ello resulte necesario para evitar el peligro de comisión de nuevos delitos, sin que puedan imponerse deberes y obligaciones que resulten excesivos y desproporcionados", a tenor de lo dispuesto en el artículo 83.1 CP con una sola excepción. En efecto, tratándose de delitos cometidos sobre la mujer por quien sea o haya sido su cónyuge, o por quien esté o haya estado ligado a ella por una relación similar de afectividad, aun sin convivencia, se impondrán siempre las prohibiciones y deberes indicados en las reglas $1 .^{\mathrm{a}}, 4 .^{\mathrm{a}}$ y 6 . $^{\mathrm{a}}$ del artículo 83.1 (art. 83.2 CP) ${ }^{10}$.

Por otra parte, en el caso en que se haya suspendido la condena a causa de la adicción a determinadas sustancias, la suspensión quedará asimismo condicionada si el condenado está sometido a tratamiento de deshabituación, a que no lo abandone hasta su finalización, si bien "no se entenderán abandono las recaídas en el tratamiento si éstas no evidencian un abandono definitivo del tratamiento de deshabituación" (art. 80.5 in fine $\mathrm{CP}$ ).

Por otra parte, el juez o tribunal puede, también, condicionar la suspensión al cumplimiento de alguno o algunos de los deberes y prohibiciones previstos en el artículo 83 CP (conocidos como "reglas de conducta"), que no podrán ser excesivos ni

10 En el supuesto que la persona a la que se ha concedido la suspensión condicionada al cumplimiento de cualquiera de las prohibiciones y deberes previstos en los artículos 83 y 84 del CP, no lleve a cabo tales mandatos, la revocación de la suspensión no opera de manera automática, según prevé el artículo 86, de manera que si "el incumplimiento de las prohibiciones, deberes o condiciones no hubiera tenido carácter grave o reiterado", el juez podrá imponer al penado nuevas prohibiciones, deberes o condiciones, o modificar las ya impuestas o prorrogar el plazo de suspensión, sin que en ningún caso pueda exceder de la mitad de la duración del que hubiera sido inicialmente fijado (art. 86.2 CP). 
desproporcionados cuando ello resulte necesario para evitar el peligro de comisión de nuevos delitos o a alguna o algunas de las prestaciones o medidas reguladas en el artículo $84 \mathrm{CP}$ (cumplimiento acuerdo de mediación, pago de una multa y trabajos en beneficio de la comunidad, principalmente).

En caso de incumplimiento "grave y reiterado" de los deberes, prohibiciones y condiciones de los artículos 83 y 84 CP impuestos, el órgano judicial podrá revocar la suspensión y ordenar la ejecución de la pena.

Como colofón de este epígrafe dedicado a la suspensión condicional de la ejecución, es preciso insistir en la necesidad de una reforma de la regulación de la suspensión al objeto de introducir la posibilidad de suspender el ingreso en prisión de la persona encargada del cuidado de sus hijos, siempre en aras del interés superior de los menores, de concurrir determinados presupuestos (como podrían ser la asunción de culpabilidad, la comisión de un delito no violento, el compromiso de velar por el bienestar de sus hijos, entre otros).

\subsection{La "sustitución" de la pena a las personas condenadas a pena privativa de libertad}

Pese a la derogación del artículo $88 \mathrm{CP}$, precepto que regulaba, con carácter general, la sustitución, esta institución pervive en el ordenamiento jurídico español por dos motivos. El primero de ellos porque se mantiene, aunque reformada, la sui generis sustitución de la pena de prisión impuesta a personas extranjeras por su expulsión del territorio nacional ${ }^{11}$. En segundo término porque, aunque formalmente viene prevista como si se tratara de una modalidad de suspensión, la sustitución de la pena de prisión sigue vigente en el Código Penal, que prevé en sus artículos 80.3 y 84.1 $\mathrm{CP}$ una sustitución obligatoria y una potestativa, respectivamente ${ }^{12}$.

En primer lugar, la sustitución obligatoria, prevista en la confusa redacción del artículo 80.3 CP, se impondrá a: (a) condenados a penas de prisión que individualmente no excedan de dos años; (b) que no sean "no habituales"; (c) si han cumplido con "la reparación efectiva del daño o la indemnización del perjuicio causado conforme a sus

11 Destaca, como novedad, que la expulsión puede afectar a cualquier persona extranjera condenada, con independencia de si reside o no legalmente en España, a diferencia del régimen anterior en que aquélla solo podía afectar a los extranjeros no residentes legalmente en España condenados a penas inferiores a seis años.

12 En efecto, como señala Barquin Sanz, "El nuevo sistema de alternativas a la ejecución de la prisión en el Derecho Penal Español: una cierta unificación”, en Cuadernos de Política Criminal, Segunda Época, n. ${ }^{\circ} 117$, diciembre de 2015, pp. 58 y 67, la sustitución pierde su independencia procedimental pero conserva su naturaleza materialmente distintiva de manera que "suspensión significa prima facie, antes y después del 1. de julio de 2015, 'no ejecución'; sustitución significa, antes y después del $1 .^{\circ}$ de julio de 2015, ejecución de una pena diferente en lugar de la pena privativa de libertad”. 
posibilidades físicas y económicas" o al cumplimiento del acuerdo a que se refiere la medida 1. del artículo 84 (esto es, el acuerdo de mediación) y (d) siempre y cuando "las circunstancias personales del reo, la naturaleza del hecho, su conducta y, en particular, el esfuerzo para reparar el daño causado así lo aconsejen”. Se trata, por tanto, de una posible medida aplicable a aquellos progenitores o cuidadores principales que pueden ser reincidentes, que hayan sido condenados por delitos relativamente leves, dado que las penas individualmente consideradas no pueden superar los dos años de prisión y que, conforme a sus posibilidades económicas, hayan reparado o sufragado la indemnización correspondiente.

En segundo término, la sustitución potestativa viene regulada en el artículo 84.1 CP, en virtud del cual, "el juez o tribunal también podrá condicionar la suspensión de la ejecución de la pena al cumplimiento de alguna de las siguientes prestaciones o medidas [...]", a saber: (a) cumplimiento del acuerdo de mediación; (b) el pago de una multa cuya extensión determinará el órgano judicial en función de las circunstancias del caso y (c) la realización de trabajos en beneficio de la comunidad, durante el tiempo que fije el juez o tribunal, "especialmente cuando resulte adecuado como forma de reparación simbólica a la vista de las circunstancias del hecho y del autor".

Los módulos de convertibilidad de la pena privativa de libertad originariamente impuesta siguen siendo los de la anterior regulación de la sustitución: cada día de prisión equivaldrá a dos cuotas multa o a un día de trabajo. Sin embargo, es necesario destacar una importante novedad y es que se prevén límites mínimos y máximos de extensión de la pena sustituta. En efecto, respecto a la sustitución obligatoria del artículo 80.3 CP para condenados no habituales se establece una extensión mínima: la pena sustituta "no podrá ser inferior a la que resulte de aplicar los criterios de conversión [...] sobre un quinto de la pena impuesta". Por su parte, el artículo 84.1 $\mathrm{CP}$ prevé una extensión máxima para aquellos supuestos de sustitución potestativa. Así, en cuanto a la pena de multa, ésta "no podrá ser superior a la que resultase de aplicar dos cuotas de multa por cada día de prisión sobre un límite máximo de dos tercios de su duración", mientras que, en términos similares, respecto a los trabajos en beneficio de la comunidad se prevé un límite máximo de dos tercios de su duración.

Por otra parte, dedicaré unas breves líneas a la sustitución aparentemente obligatoria de la pena de prisión impuesta a personas condenadas de nacionalidad distinta a la española, prevista en el reformado artículo $89 \mathrm{CP}$, que regula diversos supuestos y numerosas excepciones a aquellos supuestos, dado que ésta puede ser una medida aplicable a aquellos progenitores o cuidadores principales que han delinquido.

Las hipótesis de sustitución de la pena de prisión a personas extranjeras por expulsión podrían resumirse en las siguientes:

(a) Para penas de más de un año de prisión: en tales casos, de manera excepcional, el juez o tribunal sentenciador podrá ordenar que el condenado cumpla una parte de 
la pena en España, que no podrá ser superior a dos tercios de su extensión, “cuando resulte necesario para asegurar la defensa del orden jurídico y restablecer la confianza en la vigencia de la norma infringida por el delito". Y, en todo caso, cuando el penado acceda al tercer grado o le sea concedida la libertad condicional, el resto de la pena a cumplir se sustituirá por la expulsión del territorio nacional;

(b) Para penas de más de cinco años o varias penas que excedieran de esa duración: nuevamente, sin embargo, el juez puede acordar la ejecución de toda o parte de la pena "en la medida que resulte necesario para asegurar la defensa del orden jurídico y restablecer la confianza en la vigencia de la norma infringida por el delito"; y cumplida la parte que se hubiera determinado o cuando el penado acceda al tercer grado o a la libertad condicional, se le expulsará.

Por lo que respecta a las excepciones/atenuaciones a la "regla general" de sustituir la pena de prisión impuesta a persona extranjera por su expulsión, se destacan las siguientes: (a) la sustitución de la pena de prisión por la expulsión no procederá cuando ésta resulte desproporcionada ${ }^{13}$,"a la vista de las circunstancias del hecho y las personales del autor, en particular su arraigo en España" (art. 89.4 CP)14; (b) tratándose de un ciudadano de la Unión Europea, la expulsión solo procederá "cuando represente una amenaza grave para el orden público o la seguridad publica en atención a la naturaleza, circunstancias y gravedad del delito cometido, sus antecedentes y circunstancias personales" (segundo párrafo, art. 89.4 CP); (c) si el penado hubiera residido en España durante los últimos diez años, su expulsión solo procederá si hubiera sido condenado por alguno de los delitos relacionados en el artículo 89.4 in fine y se apreciara riesgo de reiteración delictiva en delitos de la misma naturaleza o si hubiera sido condenado por delito/s de terrorismo o cometidos en el seno de grupo u organización criminal; y, finalmente, (d) no procederá nunca la expulsión en aquellos casos en que el penado ha sido castigado por la comisión de alguno de los delitos recogidos en el artículo 89.9 CP: trata de seres humanos (art. 177 bis CP); contra los derechos de los trabajadores (art. 312 CP); emigración fraudulenta (art. 313 CP); contra los derechos de los ciudadanos extranjeros (318 bis CP) y los delitos conexos enjuiciados en la misma causa.

La sustitución de la pena de prisión a una persona extranjera por su expulsión del territorio nacional se someterá a un plazo de cinco a diez años (art. 89.4 CP), contados

13 La Circular 7/2015 de la Fiscalía General del Estado sobre la expulsión de extranjeros como medida sustitutiva de la pena prevé los criterios siguientes a fin de valorar aquella proporcionalidad: el tiempo de residencia del condenado, su situación familiar y económica, su integración laboral, social y cultural así como sus vínculos con el país de origen.

14 El arraigo, a tenor de lo previsto en la Circular 7/2015 de la Fiscalía General del Estado, citada en la nota anterior, exige una relación de convivencia real y estable y sólo puede provenir de las relaciones con los parientes próximos, entendiéndose por tales los padres y hermanos, cónyuges o parejas de hecho, e hijos -matrimoniales o no-, siempre que residan en España, u otros familiares con los que se acredite una relación estable de dependencia material o económica. 
desde la fecha de su expulsión, dependiendo de la duración de la pena sustituida y de las circunstancias personales del penado.

\section{ALTERNATIVAS PARA MINIMIZAR LOS EFECTOS DE LA PRISIÓN O ACORTAR LA CONDENA DEL PROGENITOR O CUIDADOR PRINCIPAL}

Evitar hoy en día el ingreso en prisión de los progenitores o cuidadores principales condenados a penas de más de dos años de prisión o más de cinco si han delinquido como consecuencia de su adicción será prácticamente imposible. De igual modo, si la pena impuesta a aquella persona condenada, pese a no ser de más de dos años o de cinco en el caso de usuaria de drogas, no ha sido suspendida o sustituida, de acuerdo a las previsiones analizadas en el epígrafe anterior, las posibilidades de evitar el ingreso en prisión también quedan absolutamente diezmadas, puesto que, al menos la legislación española, no prevé medidas como el control telemático o el cumplimiento de la pena en un centro, distinto a la prisión, junto a sus hijos sin antes haber sido clasificada en grado, lo cual significa que será necesario pasar por el sistema penitenciario.

En tales casos, las únicas posibilidades de acortar el tiempo de condena o, en su caso, la estancia en prisión son la concesión de un indulto o de la libertad condicional. Sin embargo, también la concesión del tercer grado puede comportar una mejora cualitativa del régimen de vida de la persona condenada ya que, entre otras ventajas, el régimen de visitas con sus hijos y las posibilidades de ejercer el rol paternal se acrecientan exponencialmente. De ahí que empecemos este epígrafe, precisamente, refiriéndonos a la clasificación en tercer grado para, después, analizar someramente la imposición del período de seguridad y la regla de cumplimiento efectivo del artículo $76 \mathrm{CP}$.

\subsection{La clasificación en tercer grado}

La clasificación, que puede ser definida como el conjunto de actividades de la Administración Penitenciaria que concluyen con una resolución mediante la cual se asigna un determinado grado a un interno (clasificación inicial) o por la cual se modifica un grado asignado anteriormente (progresión o regresión de grado) ${ }^{15}$, es una competencia atribuida a la Administración Penitenciaria en el ordenamiento jurídico español. No obstante, corresponde al juez de vigilancia resolver, de acuerdo con los estudios de los Equipos de Observación y de Tratamiento, y si procede de

15 Vid., en este sentido, Alarcón Bravo, "La clasificación penitenciaria de los internos", en Poder Judicial, n. ${ }^{\circ}$ especial III, 1988 , pp. 11 a 14. Respecto al procedimiento a seguir, regulado en el artículo 64 LOGP y artículos 242 y 243 del RP, pueden distinguirse las siguientes fases: (a) estudio y recogida de información por el Equipo de Observación y Tratamiento, una vez recibido el testigo de la sentencia firme; (b) propuesta de clasificación del centro penitenciario; (c) resolución de la Dirección General de Instituciones Penitenciarias y (d) notificación al penado y posible recurso ante el juez de vigilancia penitenciaria (art. 76.2 $f$ LOGP). 
la Central de Observación, los recursos referentes a aquella clasificación inicial, así como a las progresiones y regresiones de grado. En efecto, al amparo del previsto en el artículo 76.2.f de la Ley Orgánica General Penitenciaria (en adelante, LOGP), el juez de vigilancia penitenciaria puede decidir, siempre y cuando el interno o el Ministerio Fiscal impugnen la decisión administrativa, no sólo la clasificación inicial sino los posteriores cambios de grado.

Dada la trascendencia que, a efectos de cumplimiento de la pena, tiene la clasificación en uno o en otro grado, no sorprende la previsión legislativa del control jurisdiccional la legalidad de aquella. En efecto, como sostiene Racionero Carmona, la clasificación es un "concepto capital del derecho penitenciario" puesto que de ella dependerá "nada menos que el régimen de vida -más o menos estricto, más o menos restrictivo, con posibilidad de ejercicio de más o menos beneficios penitenciariosque el interno va a tener durante su condena"16.

Aun así, el control jurisdiccional de la decisión sobre clasificación de la persona condenada a una pena de prisión no se limita al juez de vigilancia porque los juzgados o tribunales sentenciadores asumen, por un lado, una competencia de carácter funcional, al ser los órganos judiciales encargados de resolver, en última instancia, los recursos contra las decisiones del juez de vigilancia penitenciaria sobre esta materia. Aun así, la introducción en el ordenamiento jurídico español de la nueva pena de prisión permanente revisable, la más grave de las penas del CP, ha comportado conferir también a los órganos sentenciadores la decisión sobre la clasificación en tercer grado de los condenados a esta pena, previo pronóstico individualizado y favorable de reinserción social y una vez oídos el Ministerio Fiscal e Instituciones Penitenciarias ${ }^{17}$. Esta clasificación en tercer grado de los condenados a la pena de prisión permanente revisable, de acuerdo con el previsto al artículo $36.1 \mathrm{CP}$, requiere indefectiblemente el cumplimiento efectivo de muchos años de condena y concretamente de 20 años en el supuesto de que el penado hubiera sido condenado por un delito del capítulo vII del título XXII del libro II del CP o de 15 años en el resto de casos, límites que se pueden superar, con creces, de acuerdo con lo previsto en el artículo 78 bis $\mathrm{CP}$, cuando la persona haya sido condenada por dos o más delitos y, al menos, uno de ellos esté castigado por la ley con pena de prisión permanente revisable ${ }^{18}$.

16 Racionero Carmona, Derecho penitenciario y privación de libertad. Una perspectiva judicial, Dykinson, Madrid, 1999, p. 140. La idea clave es, por lo tanto, según el mencionado autor, que "el grado de clasificación determina el régimen de vida y no a la inversa, de modo que a cada grado corresponde un régimen penitenciario, una manera de vivir, que está predeterminado en el Reglamento Penitenciario", op. y loc. cit.

17 El mismo artículo 36.1 CP in fine dispone que el penado no podrá disfrutar de permisos de salida hasta que no haya cumplido un mínimo de 12 y de 8 años, respectivamente.

18 La progresión a tercer grado requerirá, en estos supuestos, del cumplimiento en prisión de un número importante de años y concretamente, según prevé el artículo 78 bis CP: (a) de un mínimo de dieciocho años de prisión, cuando el penado lo haya sido por varios delitos, uno de ellos esté castigado con 


\subsection{La imposición del periodo de seguridad y de la regla de cumplimiento efectivo del artículo $78 \mathrm{CP}$}

Todas aquellas personas condenadas a más de cinco años de prisión pueden ver retrasada su clasificación en tercer grado en España a resultas de la imposición del llamado "período de seguridad", en virtud del cual, su clasificación no se efectuará hasta el cumplimiento de la mitad de la pena impuesta.

Esta decisión relativa al tipo de régimen que se aplicará para calcular la clasificación en tercer grado y, en general, la de los beneficios penitenciarios que acostumbran a ser más preciados por los internos (tercer grado y libertad condicional) corresponde al juez o tribunal sentenciador. En efecto, al amparo de lo dispuesto, respectivamente, en los artículos 36 y 78.1 del CP, los órganos sentenciadores podrán acordar tanto la imposición del periodo de seguridad para los condenados a más de cinco años de prisión como la de la regla de cumplimiento efectivo del artículo $78 \mathrm{CP}$ para aquellos supuestos en que la pena a cumplir resulte inferior a la mitad de la suma de las penas impuestas.

Así, el artículo $78 \mathrm{CP}$ prevé para aquellos supuestos en que, por aplicación de los límites de cumplimiento de las penas establecidos en el primer párrafo del artículo $76 \mathrm{CP}$, la pena a cumplir resultara inferior en mitad de la suma total de las penas impuestas, que los beneficios penitenciarios, los permisos de salida, la clasificación en tercer grado y el cómputo de tiempo para la libertad condicional se calculen sobre la suma de todas las penas impuestas en las sentencias. Del tenor literal del precepto y, concretamente, de la utilización de la lacónica fórmula "podrá acordar" se deduce que la aplicación del régimen previsto en el artículo $78 \mathrm{CP}$ es una facultad discrecional para el juez o tribunal sentenciador ${ }^{19}$.

pena de prisión permanente revisable y el resto de las penas impuestas sumen un total que exceda de cinco años; (b) de un mínimo de veinte años de prisión, cuando el penado lo haya sido por varios delitos, uno de ellos esté castigado con una pena de prisión permanente revisable y el resto de las penas impuestas sumen un total que exceda de quince años; (c) de un mínimo de veintidós años de prisión, cuando el penado lo haya sido por varios delitos y dos o más de ellos estén castigados con una pena de prisión permanente revisable, o bien uno de ellos esté castigado con una pena de prisión permanente revisable y el resto de penas impuestas sumen un total de veinticinco años o más. Pero es que la clasificación en tercer grado será sometida a condiciones aún más estrictas, si cabe, cuando se trate de delitos referentes a organizaciones y grupos terroristas y delitos de terrorismo del capítulo VII del título XXII del libro II de este Código, o cometidos en el seno de organizaciones criminales, puesto que los límites mínimos de cumplimiento para el acceso al tercer grado de clasificación serán de veinticuatro años de prisión, en los supuestos a que se refieren las letras $a$ y $b$ del apartado primero del artículo 78 bis, y de treinta y dos años de prisión cuando se trate de los supuestos contemplados en la letra $c$ del apartado primero del artículo 78 bis CP.

19 Este es otro de los numerosos preceptos objeto de reforma in peius introducidos en el CP por la LO 1/2015 dado que tal posibilidad existía antes de la reforma, pero, al menos, el sentenciador tenía que fundamentar la aplicación de la regla del cumplimiento efectivo en un pronóstico desfavorable sobre la peligrosidad criminal del condenado. Ningún parámetro ni criterio se contempla ahora en la norma penal y sí, en cambio, su aplicación obligatoria para determinados delitos. 
Lo mismo sucede respecto al periodo de seguridad. Así, a tenor de lo dispuesto en el artículo 36.2, en aquellos supuestos en que la duración de la pena de prisión impuesta sea superior a cinco años, el juez o tribunal sentenciador podrá ordenar que la clasificación del condenado en el tercer grado de tratamiento penitenciario no se efectúe hasta el cumplimiento de la mitad de la pena impuesta. Así mismo, el citado precepto recoge determinados delitos respecto a los cuales la aplicación del periodo de seguridad será obligatoria en cualquier caso si la pena de prisión impuesta es superior a los cinco años ${ }^{20}$.

Por su parte, el juez de vigilancia penitenciaria puede retornar a la persona al régimen ordinario de cumplimiento, previo pronóstico individualizado y favorable de reinserción social y valorando las circunstancias personales del condenado así como su evolución en el tratamiento reeducador, acordando razonadamente la aplicación del régimen general de cumplimiento, excepto en los supuestos expresamente recogidos en el mismo artículo 36.2 ${ }^{[21]}$. Preceptivamente, este órgano judicial tendrá que escuchar al Ministerio Fiscal, Instituciones Penitenciarias y resto de partes antes de resolver sobre la revocación o no del periodo de seguridad.

Como colofón, pese al período de seguridad y a la posible aplicación del régimen de cumplimiento efectivo, cabe recordar que, por lo general, proporcionalmente más mujeres que hombres disfrutan del tercer grado en España y, en consecuencia, las posibilidades de ejercer el rol maternal se acrecientan respecto de los hombres ${ }^{22}$.

\subsection{La libertad condicional}

\subsubsection{Naturaleza jurídica de la libertad condicional}

La libertad condicional en España es considerada una modalidad de suspensión de la ejecución y, por este motivo el tiempo pasado en libertad condicional no computará,

20 Concretamente, los delitos recogidos en el artículo 36.2 CP que requieren preceptivamente del cumplimiento de la mitad de la condena para que el condenado pueda ser clasificado en tercero grado son: (a) delitos referentes a organizaciones y grupos terroristas y delitos de terrorismo del capítulo VII del t. XXII del libro II; (b) delitos cometidos en el seno de una organización o grupo criminal; (c) delitos del artículo 183; (d) delitos del capítulo v del t. VIII del libro II, cuando la víctima sea menor de trece años.

21 Téngase en cuenta, a su vez, la excepción de la excepción, ya que, a tenor de lo dispuesto en el artículo 78.2 in fine $\mathrm{CP}$, tratándose de delitos referentes a organizaciones y grupos terroristas y delitos de terrorismo del capítulo vI del t. XXII del libro II o cometidos en el seno de organizaciones criminales, $y$ atendiendo a la suma total de las penas impuestas, el regreso al régimen ordinario de cumplimiento, a efectos del tercero grado, sólo será posible "cuando quede por cumplir una quinta parte del límite máximo de cumplimiento de la condena".

22 Vid. Navarro Villanueva Carmen, El encarcelamiento femenino. Especial consideración a las madres privadas de libertad, cit., pp. 64 y 65. 
en su caso, como tiempo de cumplimiento de condena. Así, si durante el periodo de suspensión, el liberado condicional comete un nuevo delito o incumple gravemente las condiciones impuestas, la libertad condicional será revocada y tendrá que cumplir toda la pena que restaba pendiente con anterioridad a la "suspensión" de la ejecución de ella.

Acorde con la aquella naturaleza jurídica, el plazo de suspensión de la ejecución del resto de la pena, que se computará desde la fecha de puesta en libertad del penado, será de dos a cinco años, a tenor de lo dispuesto en el artículo 90.5 in fine. En todo caso, añade el citado precepto, el plazo de suspensión de la ejecución y de libertad condicional no podrá ser inferior a la duración de la parte de pena pendiente de cumplimiento.

\subsubsection{La libertad condicional ordinaria: requisitos}

El Código Penal español prevé una modalidad de libertad condicional que se puede denominar ordinaria y varias modalidades especiales. Todas ellas tienen que ser aprobadas por el juez de vigilancia.

Por lo que respecta a la modalidad ordinaria de libertad condicional, de conformidad con los términos en que viene regulada en el artículo 90.1 CP (“[el] juez de vigilancia penitenciaria acordará la suspensión del resto de la pena de prisión y concederá la libertad condicional al penado que cumpla los siguientes requisitos") destaca, a priori, la obligatoriedad de su concesión, siempre que concurran los requisitos previstos en el mencionado precepto: (a) clasificación en tercer grado; (b) extinción de las tres cuartas partes de la condena; (c) buena conducta y (d) satisfacción de la responsabilidad civil.

En cambio, tratándose de los supuestos especiales de libertad condicional, parece que nos encontramos ante una decisión facultativa del JVP puesto que en todos aquellas modalidades el término utilizado por el legislador ("podrá") parece indicar su carácter potestativo. Ahora bien: tanto en el supuesto ordinario como en las diferentes modalidades especiales de libertad condicional, al menos dos de los requisitos para su concesión, concretamente la clasificación en tercer grado, para cuya concesión, a su vez, en su día se tuvieron en cuenta determinados elementos de los que subyace cierta subjetividad y la buena conducta, que también habrá que valorarla subjetivamente, convierten la pretendida "automaticidad" de la concesión de la libertad condicional en una decisión potestativa para el juez de vigilancia penitenciaria, máxime si, a tal efecto, este órgano judicial ha de valorar, según reza el artículo 90.1, "la personalidad del penado, sus antecedentes, las circunstancias del delito cometido, la relevancia de los bienes jurídicos que podrían verse afectados por una reiteración en el delito, su conducta durante el cumplimiento de la pena, sus circunstancias familiares y sociales y los efectos que quepa esperar de la propia suspensión de la ejecución y del cumplimiento de las medidas que fueren impuestas". 
A los requisitos mencionados para la modalidad ordinaria de libertad condicional es preciso añadir, al amparo de lo previsto en el artículo 90.4 CP, los que siguen: (a) el penado no podrá haber dado información inexacta o insuficiente sobre el paradero de bienes u objetos cuyo decomiso hubiera sido acordado; (b) deberá haber dado cumplimiento, conforme a su capacidad, al compromiso de pago de las responsabilidades civiles a que hubiera sido condenado; (c) el penado no deberá haber facilitado información inexacta o insuficiente sobre su patrimonio; (d) tratándose de una condena por alguno de los delitos contra la Administración Pública, el penado deberá haber dado cumplimiento a las responsabilidades pecuniarias o a la reparación del daño económico causado a la Administración a que hubiera sido condenado.

\subsubsection{Otras modalidades de libertad condicional}

En cuanto a las modalidades especiales de libertad condicional, destaca, en primer lugar, aquélla para personas que se encuentren cumpliendo su primera condena de prisión, siempre que la duración de ésta sea inferior a los tres años y no haya sido impuesta por la comisión de un delito contra la libertad e indemnidad sexuales (art. 90.3 in fine) o de terrorismo o cometidos en el seno de organizaciones criminales (art. 90.8 in fine). A partir de los dos requisitos mencionados (primera condena y de menos de tres años) el juez de vigilancia, con carácter excepcional, a tenor de lo dispuesto en el artículo 90.3 CP, podrá conceder la libertad condicional si, además, el condenado: (a) ha extinguido la mitad de la condena; (b) está clasificado en tercer grado; (c) tiene buena conducta: (d) ha satisfecho la responsabilidad civil y (e) ha realizado durante el cumplimiento de la pena, actividades laborales, culturales $u$ ocupacionales, "bien de forma continuada, bien con un aprovechamiento del que se haya derivado una modificación relevante y favorable de aquellas de sus circunstancias personales relacionadas con su actividad delictiva previa".

Por otra parte, se prevén sendos tipos de libertad condicional avanzada que exigen que el condenado haya desarrollado durante el cumplimiento de su pena actividades laborales, culturales u ocupacionales en los mismos términos expresados en el artículo 90.3 CP para la persona que esté cumpliendo su primera condena siendo ésta inferior a los tres años de prisión. Se trata, en primer lugar, de la libertad condicional avanzada del artículo 90.2 ab initio, que exige para su concesión, amén de las actividades ya mencionadas y de los requisitos de la libertad condicional ordinaria, la extinción de dos terceras partes de la condena. En segundo término, el artículo 90.2 in fine prevé otra modalidad avanzada, con idénticos requisitos a la anterior, excepto el de haber extinguido las dos terceras partes de la condena y añadiendo la acreditación de la participación "efectiva y favorable" del liberado condicional en programas de reparación a las víctimas o programas de tratamiento o desintoxicación, en su caso. En este supuesto se establece la posibilidad de poder adelantar la concesión de la libertad condicional en relación con el plazo previsto en el apartado anterior, una vez extinguida la mitad de la condena, "hasta un máximo de noventa días por cada año transcurrido de cumplimiento efectivo de condena". 
Por su parte, el artículo $91 \mathrm{CP}$ contempla una libertad condicional por razones humanitarias para aquellos penados que "hubieran cumplido la edad de setenta años o la cumplan durante la extinción de la condena y reúnan los requisitos exigidos en el artículo anterior, excepto el de haber extinguido las tres cuartas partes o, en su caso, la mitad de la condena" así como para aquellos penados "enfermos muy graves con padecimientos incurables", respecto de los cuales tampoco se exige ningún quantum de cumplimiento de la condena ${ }^{23}$. Por otro lado, quedan excluidas de estas dos modalidades avanzadas de libertad condicional aquellas personas condenadas por la comisión de delitos de terrorismo del capítulo vII del título XXII del libro II del CP o por delitos cometidos en el seno de organizaciones criminales.

También es preciso hacer mención de las especialidades relativas a la libertad condicional de terroristas y personas integradas en bandas organizadas, dejando de lado la señalada excepción, en virtud de la cual no podrán disfrutar de ninguna de las modalidades previstas en los artículos 90.2 y 3 CP. En tales supuestos, se requerirá mostrar "signos inequívocos de haber abandonado los fines y los medios de la actividad terrorista" así como colaboración activa con las autoridades en los términos previstos en el artículo $90.8 \mathrm{CP}$.

Mención especial requiere la libertad condicional de las personas condenadas a prisión permanente revisable, la más grave de las penas previstas en nuestro ordenamiento jurídico y mediante cuya revisión cada dos años, a partir de que el condenado haya pasado, como mínimo, 25 años en prisión, prevista en el artículo $92 \mathrm{CP}$, parece querer salvar el legislador su clara vulneración a numerosos derechos fundamentales, como el derecho a la reinserción social y a la reeducación, a la libertad, a la dignidad, por citar algunos así como a los principios generales de nuestro sistema jurídico.

La preceptiva revisión de la cadena perpetua, que dará lugar, en su caso, a la libertad condicional, será competencia no ya del juez de vigilancia penitenciaria sino del tribunal sentenciador que la impuso, si bien también puede ser solicitada por el condenado. Así, según prevé el artículo 92.4 in fine, "el tribunal deberá verificar, al menos cada dos años, el cumplimiento del resto de requisitos de la libertad condicional. El tribunal resolverá también las peticiones de concesión de la libertad condicional del penado, pero podrá fijar un plazo de hasta un año dentro del cual,

23 Respecto del procedimiento "simplificado", previsto para la concesión de la libertad condicional en aquellos casos en que el peligro para la vida del interno, a causa de su enfermedad o su edad avanzada, es patente, el artículo 91.3 CP faculta al juez de vigilancia penitenciaria a decidir, tras valorar la falta de peligrosidad, "sin más trámite que requerir al centro penitenciario el informe del pronóstico final". La novedad, respecto a la anterior regulación, radica en que se introduce una obligación para el penado, cual es la de "facilitar al servicio médico penitenciario, al médico forense o a aquel otro que se determine por el juez o tribunal, la información necesaria para poder valorar sobre la evolución de su enfermedad", cuyo incumplimiento, a tenor de lo dispuesto en el artículo 91.3 in fine, puede dar lugar a la revocación de la libertad condicional. 
tras haber sido rechazada una petición, no se dará curso a sus nuevas solicitudes". A tal efecto, el tribunal resolverá sobre la suspensión de la pena de prisión permanente revisable tras un procedimiento oral contradictorio en el cual intervendrán el Ministerio Fiscal y el penado, asistido por su abogado.

Para concluir, es preciso recordar, de nuevo, que también más mujeres que hombres suelen disfrutar en España de la libertad condicional ${ }^{24}$. De todos modos, sólo unas líneas para señalar el deseo de que la pena de prisión permanente revisable sea derogada en un futuro próximo. Se trata de una pena inhumana y contraria al derecho a la reinserción por el que nuestra Constitución optó. Además, en el caso de personas condenadas con hijos menores, una pena de este tipo anula, por completo, las posibilidades del ejercicio de la paternidad.

\subsection{El indulto}

\subsubsection{Concepto y problemas constitucionales que plantea el indulto}

El indulto puede ser definido, en clave española, como un acto del rey, refrendado por el presidente del Gobierno o por el ministro de Justicia, por el cual se remite total o parcialmente la pena impuesta por sentencia firme. De este modo, el indulto será una manifestación del derecho de gracia conforme al cual se perdona al penado el todo o parte de una pena o se le conmuta por otra pena más leve.

Hoy en día, el indulto es una potestad que corresponde al gobierno de la nación, pese a que, simbólicamente, se atribuye al rey y que, al igual que antiguamente, le permite dejar sin efecto, en todo o en parte, una decisión que proviene del poder judicial. Por esta razón, se puede afirmar que el indulto supone, sin duda, una excepción al monopolio jurisdiccional del Poder Judicial ${ }^{25}$. Así, el ejercicio del derecho de gracia implica la presencia de los tres poderes del Estado. De una parte, la del poder legislativo, dado que la Constitución establece que el rey ejercerá aquella potestad "con arreglo a la ley"; de otra, la del poder ejecutivo, puesto que el indulto en tanto que acto del rey, ha de ser refrendado por el gobierno para adquirir validez. Finalmente, pese al silencio de la Constitución en cuanto a la intervención del poder judicial, ésta se materializa, no sólo porque el indulto deja sin efecto, total o parcialmente, una decisión emanada de aquel poder, sino porque el tribunal sentenciador tendrá una activa participación en el procedimiento para tramitar el derecho de gracia y, posteriormente, será, también el encargado de ejecutar el decreto de concesión del indulto.

24 Vid. Navarro Villanueva Carmen, El encarcelamiento femenino, cit., pp. 64 y 65.

25 En este sentido se pronuncia Manuel Aragón en su prólogo a la obra de Aguado Renedo, Problemas constitucionales del ejercicio de la potestad de gracia, Civitas, Madrid, 2001, p. 17. 
Pese a las críticas que tal institución ha recibido a lo largo del tiempo, el legislador sigue manteniendo el polémico derecho de gracia, que entronca con los postulados propios del Ancien Régime y que tan mal se aviene con las exigencias fundamentales de un Estado de derecho ${ }^{26}$. Una de las críticas más ásperas proviene ya de Beccaria, en cuya opinión la clemencia y el perdón son innecesarios en un ordenamiento en el cual "las penas sean más dulces y el enjuiciamiento regular y expeditivo"27. Y, como sostenía el citado autor, la clemencia debería ser virtud del legislador pero no del ejecutor de las leyes ${ }^{28}$.

En efecto, mediante la concesión de un indulto, el gobierno deja sin efecto una parte o la totalidad de una decisión emanada de un órgano judicial, es decir, perteneciente al poder judicial. Y ello, pese a la previsión constitucional contenida en el artículo 118, en virtud de la cual es obligado cumplir las sentencias y demás resoluciones judiciales firmes. Cierto es, por otra parte, como sostiene parte de la doctrina, que el indulto es un instrumento sometido a ciertos límites que derivan expresa o implícitamente de la Ley del indulto de 1870 (en adelante, LInd), aún vigente, o del $\mathrm{CP}^{29}$. De manera que, si bien la decisión final acerca de la conveniencia o no de otorgar el indulto corresponde al Gobierno, esta decisión está sujeta a un "difuso" control parlamentario ${ }^{30}$.

26 En este sentido, vid., por todos, Pacheco, Lecciones de derecho penal I, XXI. Este autor sostiene que el indulto excluye, por naturaleza, toda regla y añade que "su verdadero carácter es la arbitrariedad y la arbitrariedad no puede menos de ser arbitraria".

27 Beccaria, De los delitos y de las penas, trad. Juan Antonio de las Casas, Alianza Editorial, Madrid, 1968,pp. 111 y ss.

28 Beccaria, De los delitos y de las penas, op. y loc. cit. La clemencia, a juicio de este autor, debe resplandecer en el Código y no en juicios particulares y ello porque hacer ver a los hombres que se pueden perdonar los delitos, o que la pena no es la consecuencia necesaria, supone fomentar la esperanza de la impunidad, y es hacer creer que, pudiéndose perdonar, las condenas no perdonadas son más bien violencias de la fuerza que emanaciones de la justicia. No acaban aquí los inconvenientes que acarrea el indulto, ya que esta institución cuestiona el papel que la Constitución otorga a cada uno de los poderes del Estado, esto es, el fundamental principio de división de poderes, ya que supone conceder al poder ejecutivo una potestad que, por su naturaleza, afecta al núcleo esencial del contenido propio de la potestad jurisdiccional. Vid. Aguado Renedo, Problemas constitucionales del ejercicio de la potestad de gracia, op . cit., que dedica el grueso de su obra al análisis de los conflictos que entraña el indulto en tanto que excepción a la exclusividad de la potestad jurisdiccional.

29 Vid. por todos Linde Paniagua, "La clemencia (amnistía e indulto) a la luz de la jurisprudencia de los Tribunales Supremo y Constitucional y del CP de 1993", en B. I. M. J., n. ${ }^{\circ} 1823$, pp. 14-15. Señala el citado autor como límites del indulto el propio procedimiento previsto en la Ley de 1870. Asimismo, recuerda que el indulto no puede utilizarse como reforma, por la vía de hecho, de leyes consideradas injustas con carácter indefinido. En su opinión, si las leyes son injustas el Parlamento debería modificarlas o derogarlas. Por último, alerta de la utilización masiva de la vía del indulto particular ya que tal proceder se equipararía a un indulto general, reprobado, según Linde Paniagua, por la doctrina progresista española y prohibido expresamente por la Constitución.

30 La idea del control parlamentario del indulto viene desarrollada por López Aguilar, "Una reflexión a propósito del control parlamentario del ejercicio del derecho de gracia", en Revista de las Cortes Generales, n. ${ }^{\circ} 37$, primer cuatrimestre, 1996, pp. 329 a 342. 
El indulto, por otra parte, puede poner en peligro otro principio fundamental del Estado de derecho. Me refiero al derecho a la igualdad. En efecto, si el ejercicio del derecho de gracia da como resultado una decisión discrecional del poder ejecutivo, que no está obligado a motivar desde la reforma de la Ley del Indulto de 1988, nada impide que en un caso se conceda el indulto y en otro similar, no.

Por otra parte, una de las razones aducidas por los partidarios del indulto ha sido su utilización como instrumento para potenciar la reinserción de personas condenadas probadamente redimidas, de manera que la buena conducta durante el cumplimiento se vería compensada con la concesión de un indulto. De todos modos, en mi opinión, los beneficios penitenciarios previstos en la Ley constituyen un recurso preferible para reducir la condena de aquella persona rehabilitada al indulto porque, al menos, aquellos beneficios están sometidos a determinados requisitos. Además, su concesión o denegación es susceptible de recurso ante la jurisdicción. Por el contrario, la concesión o denegación del indulto es irrecurrible ya que al tratarse de una decisión discrecional de quien ejerce la prerrogativa, no está obligado a concederla.

En definitiva, es preferible hacer uso de los instrumentos que la propia legislación penitenciaria ofrece para reconocer los avances en la rehabilitación y reeducación de los penados ${ }^{31}$, máxime sabiendo que el indulto podría llegar a ser un elemento perturbador en el ámbito penitenciario al no recaer necesariamente en el penado que se encuentre en mejores condiciones de reinserción ${ }^{32}$.

Y, sin embargo, dadas las nulas posibilidades de acortar hoy en día las condenas, preciso es reconocer que el indulto, con todos sus defectos, puede ser una de las escasas vías de acortamiento de las penas a los progenitores o cuidadores principales con niños a su cargo.

\subsection{Requisitos para la concesión del indulto}

Los requisitos que deben concurrir en la persona que sea propuesta para la concesión de un indulto, a partir de una interpretación conjunta de los artículos 1 y 2 LInd, son los siguientes:

(a) En primer lugar, es necesario que haya recaído sentencia penal condenatoria, que, a su vez haya adquirido firmeza. Es decir, la concesión del indulto no puede tener lugar en favor de los investigados/encausados respecto de los cuales no se ha dictado sentencia firme. Como señala Llorca Ortega, "el indulto gracia penas, no delitos".

31 Así, si el interno evoluciona favorablemente es conveniente clasificarlo en tercer grado, que goce cada vez de más prerrogativas y que vea avanzar la fecha de su puesta en libertad.

32 Vid., en este sentido, Llorca Ortega, La ley de indulto (Comentarios, jurisprudencia, formularios y notas para su reforma), Valencia, 1995, p. 18. 
Así se comprende la rotundidad de la ley al sostener que la pena indultada puede provenir de cualquier clase de delito ${ }^{33}$;

(b) Por otra parte, para que pueda tener lugar el otorgamiento del indulto, es preciso que la persona condenada se encuentre a disposición del tribunal sentenciador para el cumplimiento de la condena. De todas formas, la interpretación de este requisito no es, en absoluto, pacífica. Así, un sector doctrinal ha interpretado el artículo 2.2 como exigencia inexcusable de que el posible beneficiario del indulto se halle cumpliendo condena. Otros autores e incluso la propia Administración han entendido que el penado se hallaba a disposición del tribunal si habitaba en la demarcación de la audiencia respectiva o se encontraba en condiciones de comparecer en cualquier momento en que fuese llamado ${ }^{34}$. Hoy en día la interpretación que nos parece más correcta es la de entender que se encuentra a disposición del tribunal quien está localizado y comparece cuantas veces es llamado (art. 530 de la LECr) y, consecuentemente, el requisito analizado sólo excluye a quienes se hallen en situación procesal de rebeldía ${ }^{35}$;

(c) Finalmente, el artículo 2.3 LInd excluye del indulto a los "reincidentes en el mismo o en otro cualquiera delito por el cual hubiesen sido condenados por sentencia firme", pero se "exceptúa, sin embargo, el caso en que, a juicio del tribunal sentenciador, hubiese razones suficientes de justicia, equidad o conveniencia pública para otorgarle la gracia" ${ }^{36}$.

En cualquier caso, la ley no prohíbe expresamente el indulto de la persona que fue ya indultada, pese a las críticas que históricamente suscitó tal posibilidad ${ }^{37}$.

33 Llorca Ortega, La ley de indulto (Comentarios, jurisprudencia,formularios y notas para su reforma), p. 25. Este autor relata cómo históricamente estuvieron excluidos de indulto los denominados "delitos feos o enormes" y los casos de hermandad. A pesar de ello, se utilizaron numerosos subterfugios por las autoridades para eludir la excepción.

34 Vid. la Real Orden del 24 de diciembre de 1914, derogada por el artículo 4. ${ }^{\circ}$ de la Orden del Ministerio de Justicia del 10 de septiembre de 1993.

35 En el mismo sentido se pronuncia la Fiscalía General del Estado en la Consulta 1/1994, del 19 de julio, sobre la posibilidad de suspensión del inicio de la ejecución de condenas penales ante una solicitud de indulto, publicada en el Boletín de Información del Ministerio de Justicia, del 25 de enero de 1995 , pp. 408 a 417.

36 El tercer párrafo del artículo 2. ${ }^{\circ}$ de la LInd ha sido modificado por la Ley 1/1988, del 14 de enero, cuya redacción primitiva era la siguiente: "Los reincidentes en el mismo o en otro cualquier delito por el cual hubiesen sido condenados por sentencia firme. Se exceptúa, sin embargo, el caso en que a juicio del Tribunal sentenciador, o del Consejo de Estado, hubiese razones suficientes de justicia, equidad o conveniencia pública para otorgarles la gracia".

37 Así, por ejemplo, Llorca Ortega, La ley de indulto..., cit., p. 22, recoge la opinión de Melchor de Jovellanos que en un informe sobre el ejercicio de la regia prerrogativa de gracia para el rey Carlos III sostenía: "El que delinque después de haber sido indultado, hace presumir que le hizo falta el castigo para la enmienda, y después de haber abusado de la primera gracia, queda menos acreedor de segunda". 


\subsection{El procedimiento para la concesión del indulto}

Desde el punto de vista de la iniciación del procedimiento de indulto, es preciso destacar, con carácter previo, la amplia legitimación para su incoación. En efecto, la iniciativa para pedir el indulto puede proceder del órgano judicial, del ministerio fiscal, del condenado, de cualquier persona en su nombre, del propio gobierno o de la Administración Penitenciaria.

En cuanto a la tramitación de la propuesta de indulto, pueden distinguirse las siguientes fases:

1. . . La solicitud se dirigirá al ministro de Justicia, bien directamente, bien por conducto del tribunal sentenciador, del director del centro penitenciario o del gobernador civil de la provincia en que el penado se halle cumpliendo condena (art. 22 LInd). Recibida la solicitud, será remitida por el ministro de Justicia al tribunal sentenciador, para informe del órgano judicial, según dispone el artículo 2.3 LInd.

2. ${ }^{a}$. Una vez determinado éste último, habrán de practicarse las diligencias que a continuación se señalan. En primer lugar, será preciso elaborar un informe sobre la conducta del penado. El órgano judicial solicitará, a tal efecto, información al director del centro penitenciario donde el condenado esté cumpliendo la pena. El informe contendrá, entre otros extremos que después mencionaremos, la conducta observada por el condenado tras la sentencia firme, así como las pruebas o indicios de su arrepentimiento, sin perjuicio de que, en su caso, como se indicará, el propio penado en la solicitud de indulto ya hubiera aportado informes de la Administración Penitenciaria.

3. ${ }^{\text {a }}$ Posteriormente, de acuerdo con lo dispuesto en el artículo 24 LInd, deberá oírse a la parte ofendida por el delito si la hubiera y al Ministerio Fiscal.

4. '. Una vez cumplidos estos trámites, el juez o tribunal sentenciador deberá elaborar su propio informe, en el que se hará referencia a una amplia serie de puntos fijados en el artículo 25 de la LInd. Así mismo, en dicho informe, el órgano sentenciador se pronunciará sobre si estima o no procedente la concesión del indulto y, en su caso, acerca de la forma de éste.

5. a . Una vez elaborado el informe, el tribunal sentenciador lo remitirá al ministro de Justicia, junto con la certificación del Registro Central de Penados y Rebeldes, o sea, la hoja histórico-penal, el testimonio de la sentencia y "los demás documentos que considere necesarios para la justificación de los hechos” (art. 26 LInd).

6. ${ }^{\text {. }}$ Recibida la documentación en el Ministerio de Justicia, éste formulará la propuesta motivada de resolución que se elevará al Consejo de Ministros. En el caso de ser concedido el indulto, lo hará a través de un real decreto, que se publicará en 
el Boletín Oficial del Estado, con la firma del rey, refrendada, por lo general, por el ministro de Justicia (art. 30 de la LInd).

El decreto de indulto, carente de toda motivación desde la reforma de la LInd por la Ley 1/1988 del 14 de enero, se limita a recoger datos objetivos, tales como el nombre del beneficiario, el delito cometido, la pena impuesta, el año de comisión de los hechos delictivos y el órgano que lo propone. Obviamente, el decreto de concesión hace expresa mención de la pena indultada y, en su caso, de las condiciones a que se somete.

Con la concesión del indulto se materializa, por tanto, la intromisión del poder ejecutivo en el ejercicio de una de las principales atribuciones conferidas al poder judicial. Ello no obstante, aprobada la gracia, el poder judicial volverá a intervenir. En efecto, el tribunal sentenciador es el órgano que tiene encomendada la aplicación del indulto, de acuerdo con lo previsto en el artículo 31 LInd. De este modo, el tribunal procederá, con carácter previo, a efectuar una nueva liquidación de la condena, con el fin de conocer la nueva fecha de cumplimiento efectivo de la pena.

\subsection{El indulto penitenciario}

El Reglamento Penitenciario español regula el denominado "indulto penitenciario" en su artículo 206, dentro del capítulo II de su título VIII, dedicado a la libertad condicional y a los beneficios penitenciarios, a tenor del cual "la Junta de Tratamiento, previa propuesta del Equipo Técnico, podrá solicitar del juez de vigilancia penitenciaria, la tramitación de un indulto particular, para los penados en los que concurran, de modo continuado durante un tiempo mínimo de dos años y en un grado que se le pueda calificar de extraordinario, todas y cada una de las siguientes circunstancias: (a) buena conducta; (b) desempeño de una actividad laboral normal, bien en el Establecimiento o en el exterior, que se pueda considerar útil para su preparación para la vida en libertad; (c) Participación en las actividades de reeducación y reinserción social". La tramitación de esta modalidad de indulto, de acuerdo al párrafo segundo de la mencionada disposición, se llevará a cabo con arreglo a lo dispuesto en la vigente legislación del derecho de gracia y en las disposiciones que la complementen o modifiquen.

En cuanto a los requisitos que deben concurrir en la persona condenada para que pueda ser propuesto su indulto, es preciso señalar que adolecen de una gran imprecisión. Aun así, trataré delimitar con mayor precisión el alcance de dichos requisitos:

(a) Cuando el Reglamento exige un "grado que se pueda calificar de extraordinario", se está refiriendo, claramente, al tercer grado, y ello porque que la clasificación en primer grado o régimen cerrado, e incluso en segundo grado o régimen ordinario, se contradice con la finalidad perseguida por el indulto penitenciario. En definitiva, mediante este indulto se pretende no prolongar la privación de libertad de aquellas personas que demuestren la normalización de sus pautas de comportamiento, y a 
los cuales el cumplimiento efectivo de la totalidad de la pena causaría efectos más negativos que positivos en orden a su futura reinserción (art. 25.2 CE).

(b) En cuanto al requisito relativo a la observancia de "buena conducta", debe ser entendido como ausencia de sanciones disciplinarias graves. Al menos, esta interpretación es algo más objetiva que la referencia abstracta a la conducta de la persona condenada que, por su carácter indeterminado, pone en entredicho el principio de legalidad. De todas formas, en la lógica del CP, este requisito es superfluo y reiterativo, puesto que ya se habrá tenido en cuenta para conceder el tercer grado.

(c) Respecto al "desempeño de una actividad laboral normal, bien en el establecimiento o en el exterior, que se pueda considerar útil para su vida en libertad", me parece acertada la interpretación que de este requisito hizo, en su día, la Circular de la Dirección General de Instituciones Penitenciarias española del 8 de marzo de 1990. A tenor de ésta, se deben considerar incluidas "todas aquellas actividades que hacen adquirir hábitos laborales, por su desempeño regular, constante y ordenado, así como los distintos cursos de capacitación profesional debiendo obtener en el desempeño de todas ellas un buen rendimiento" 38 . Es cierto que a pesar de la amplitud de dicha interpretación existe un generoso margen de valoración, pero en cualquier caso considero que es la interpretación más acorde con las posibilidades reales de trabajo de nuestros centros penitenciarios.

(d) Finalmente, en cuanto al requisito de la "participación en actividades de reeducación y reinserción social", cualquier actividad organizada por el centro penitenciario con aquella finalidad serviría para cubrir este requisito. Aquí nuevamente debe hacerse una interpretación lo más amplia posible, siempre que quede suficientemente acreditada la participación del interno.

Los mencionados requisitos deben concurrir en el interno durante un tiempo superior a dos años.

El expediente de indulto penitenciario se inicia a propuesta del Equipo Técnico, el cual tras el estudio del interno decide elevar dicha propuesta a la Junta de Tratamiento. Esta última será quien solicite al juez de vigilancia la tramitación del indulto. Por lo que atañe a la tramitación del indulto penitenciario, se sigue el cauce procedimental analizado. No obstante, en este supuesto puede simplificarse, en parte, el procedimiento, porque algunos de los informes y datos que exige la Ley de Indulto se hallan ya recogidos en la propuesta de indulto que realiza la Junta al juez de vigilancia.

38 Vid. la circular del 8 de marzo de 1990 de la Dirección General de Instituciones Penitenciarias, que fija un marco orientativo y dando homogeneidad a los criterios para la aplicación del artículo 257 del Reglamento Penitenciario, en Revista de Estudios Penitenciarios, n. . 243, 1990, p. 142. 
A su vez, éste último elabora su propio informe, al igual que el fiscal de vigilancia penitenciaria, sobre la conveniencia o no de conceder el beneficio del indulto ${ }^{39}$.

\subsection{Los indultos a mujeres condenadas y valoración final del derecho de gracia}

En términos absolutos, muchos más hombres que mujeres han sido indultados en España. Sin embargo, las cifras también confirman que las mujeres gozan, en mayor medida que los hombres, del derecho de gracia. Efectivamente, el número de mujeres indultadas ha experimentado desde el año 1986 un aumento considerable. Así, si en 1986 se indultó al 3\% de mujeres frente al 97\% de hombres, en 2016 las cifras de personas indultadas en España fueron: el $26 \%$ de mujeres y el $74 \%$ de hombres.

El incremento de mujeres beneficiadas por el derecho de gracia ha sido atribuido a una mayor sensibilidad para con ellas a resultas de las cargas familiares que asumen así como a la constatación de la menor gravedad de los delitos por los que son condenadas ${ }^{40}$.

Para finalizar este epígrafe dedicado al indulto, es preciso insistir en la necesidad de interpretar restrictivamente las normas que autorizan y regulan el ejercicio de la gracia, con el fin de conciliar su existencia, como afirma Rubio Llorente, con el Estado de derecho y, en particular, con el principio de igualdad ante la ley ${ }^{41}$. Y es que el indulto, en tanto que interferencia del poder ejecutivo en la misión encomendada a los órganos judiciales, ha de ser aplicado de manera muy excepcional y utilizado de la manera más objetiva posible ${ }^{42}$. Ello comporta, necesariamente, el deber de motivar tanto la concesión como la denegación de aquel, especialmente en aquellos casos en que la negativa a concederlo recae sobre un supuesto de hecho similar a otro en el que sí fue otorgado, con el fin de no poner en peligro el principio de igualdad.

39 El informe del juez de vigilancia penitenciaria puede no ser coincidente con el que, con carácter general, debe emitir también el órgano sentenciador en el procedimiento de concesión del indulto. En estos casos, habida cuenta de la naturaleza de esta modalidad de indulto y de los motivos en que se funda, estamos de acuerdo con Llorca Ortega, La ley de indulto, cit., p. 122, que considera, con buen criterio, que debe tener más relevancia el informe del juez de vigilancia. La razón es obvia, a nuestro juicio. Este órgano judicial se encuentra mucho más próximo al interno y ha podido seguir la evolución de éste a lo largo del tiempo que ha estado cumpliendo la pena de privación de libertad, cuya reducción se pretende con el indulto. De todas formas, por la propia naturaleza del indulto, el Consejo de Ministros puede otorgarla o no, con independencia del contenido del informe del juez de vigilancia y del tribunal sentenciador.

40 Vid. al respecto Herrero Bernabé, El derecho de gracia: indultos, tesis doctoral, UnED, Madrid, 2012, pp. 499 a 501, en [http://e-spacio.uned.es/fez/eserv/tesisuned:Derecho-Iherrero/Documento.pdf].

41 Rubio Llorente, en su artículo "Quizás España no vaya tan bien”, publicado en El País del 25 de octubre de 1999.

42 En esta misma línea, la Fiscalía General del Estado subrayaba en su consulta del 19 de julio de 1994 el carácter excepcional del indulto, dado que no se trata de un derecho sino de una gracia. 
En consecuencia, sería necesario limitar aquel poder conferido al poder ejecutivo, sometiéndolo a un control diferente del social y del parlamentario. En efecto, hay que reconocer que, en última instancia, el indulto está sometido a control por parte de la sociedad. Sin embargo, este control sólo surge en aquellos casos más mediáticos, en los que los medios de comunicación dan a conocer a la población la concesión de la gracia a determinada persona. Por otra parte, hay que tener en cuenta el posible control parlamentario del indulto, como el de cualquier actuación del gobierno, a tenor de lo dispuesto en el artículo 66.2 CE. Ahora bien: ambos tipos de controles se han revelado insuficientes. Por esta razón, en caso de mantener el polémico derecho de gracia en nuestro ordenamiento jurídico, es preciso abogar por un control jurisdiccional del indulto ${ }^{43}$.

\section{REFLEXIÓN FINAL}

El objetivo final de este trabajo residía en mostrar las posibles alternativas al uso de la prisión para los progenitores o cuidadores principales de menores de edad que, presuntamente, han cometido un delito. Dicho análisis se llevó a cabo de manera lineal, esto es, distinguiendo las diversas fases del proceso penal. De este modo, el estudio se inició con algunas propuestas para evitar el ingreso en prisión del progenitor o cuidador principal con carácter preventivo, esto es, con anterioridad al juicio. Seguidamente, se estudiaron las diversas alternativas que la legislación española ofrece a las personas condenadas para evitar su ingreso en prisión y que se reducen, hoy en día, a la suspensión condicional de la ejecución, que incluye, a su vez, la "derogada" sustitución de la pena de prisión por multa o trabajos en beneficio de la comunidad. Para concluir, fueron analizadas diferentes posibilidades que pueden suponer un acortamiento del tiempo en prisión, como la libertad condicional o la concesión del indulto o aquéllas que comportan una mejora cualitativa del tiempo en prisión, como sería la concesión del tercer grado.

Conocidos los devastadores efectos que el encarcelamiento de un progenitor o cuidador principal provoca en los menores a su cargo y el elevado número de niños que tienen a sus padres privados de libertad en España, debemos centrar nuestros esfuerzos en la búsqueda de nuevas alternativas a la prisión y en reforzar las existentes con el fin de minimizar las negativas consecuencias y los severos daños, especialmente psíquicos, que para los hijos tiene el ingreso en prisión de sus padres. Según vimos, el ordenamiento jurídico español no ofrece demasiadas soluciones y

43 La escasa jurisprudencia al respecto ha venido manteniendo la posibilidad de controlar judicialmente el indulto, al menos "en el aspecto puramente procedimental de cumplimiento de los trámites establecidos para su adopción, que pueden ser fiscalizados, en su aspecto meramente administrativo por la Jurisdicción" (auto del Tribunal Supremo del 31 de enero de 2000, RJ: 506). Vid., ampliamente, Pérez Francesch, J. L. y Domínguez García, F. El indulto como acto del gobierno: una perspectiva constitucional (especial análisis del “caso Liaño”), cit., p. 45. 
las que prevé no siempre van a poder ser aplicadas a los progenitores o cuidadores principales que, presuntamente, han cometido un delito.

En definitiva, los progenitores o cuidadores principales encarcelados van a requerir de apoyo social, familiar, emocional y legal para mantener sus roles de cuidadores durante el tiempo de la condena y a posteriori. De ahí que sea preciso "invertir" en las estrategias multidimensionales que sean necesarias para poder ofrecer tales apoyos. Y ello en beneficio de unas personas que delinquieron, para que no repitan esa experiencia, pero sobre todo en beneficio de unos niños, que no cometieron delito y tienen derecho a vivir con su principal cuidador. Así mismo, la persona cuidadora debe contar, una vez está en libertad, con los recursos económicos imprescindibles para evitar la reincidencia. De ahí que durante el cumplimiento de la pena será preciso ofrecerle las habilidades necesarias, caso de carecer de ellas, para que pueda incorporarse al mundo laboral.

El derecho del niño a vivir con sus padres, a crecer en un ambiente saludable y a disfrutar, en definitiva, de una infancia feliz ha de prevalecer sobre el derecho al castigo de la persona que, con anterioridad al encarcelamiento, era su principal cuidador y que en muchos casos será la madre. Si el castigo del progenitor, tras la exploración de todas y cada una de las posibilidades, no puede ser otro que la prisión, se ha de procurar que el tiempo de condena sea el mínimo imprescindible, que se cumpla en un régimen de semilibertad y que los contactos con los hijos se lleven a cabo con asiduidad y en locales apropiados.

\section{REFERENCIAS}

Aguado Renedo, Problemas constitucionales del ejercicio de la potestad de gracia, Civitas, Madrid, 2001.

Alarcón Bravo, "La clasificación penitenciaria de los internos”, en Poder Judicial, n. ${ }^{\circ}$ especial III, 1988.

Álvarez García y Queralt Jiménez Argelia, “La prisión atenuada como medida cautelar aplicable con carácter general, y la vigencia de la Ley de 10 de septiembre de 1931", en Diario La Ley, n. ${ }^{\circ} 6174$ del 24 de enero de 2005.

Asencio Mellado, José María, La prisión provisional, Civitas, Madrid, 1987.

Baldwin, Lucy y Epstein, Rona, Short but not sweet: a study of the impact of short custodial sentences on mothers \& their children, Montfort University, julio, 2017.

Barnes, Sandra y Stringer, Ebonie Cunnigham, "Is motherhood important? Imprisoned Women's maternal experiences before and during confinement and their postrelease expectations", en Feminist Criminology, vol. 9 (I), 2014. 
Cadenas, Cortina, "La prisión provisional en el derecho comparado y la experiencia europea continental”, en Andrés Ibáñez (coord.), Detención y prisión provisional, Cuadernos de Derecho Judicial, CGPJ, Madrid, 1996.

Carlson, Joseph, "Prison nursery 2000: A five-year review of the prison nursery at the Nebraska Correctional Center for Women", Journal of Offender Rehabilitation, vol. 33 (3), 2001.

Casey-Acevedo, Karen; Bakken, Tim y Karle, Adria, "Children visiting mothers in prison: the effects on mother's behavior and disciplinary adjustment", en The Australian and New Zealand Journal of Criminology, vol. 37, n. ${ }^{\circ}$ 3, 2004.

Clark, Judith, "The impact of the prison environment on mothers", en The prison journal, vol. 75, n. ${ }^{\circ}$ 3, September, 1995.

Convery Una y Moore, Linda, "Children of imprisoned parents and their problems", en Scharff-Smith Peter y Gampell Lucy (eds.), Children of imprisoned parents, The Danish Institute of Human Rights, European Network for Children of Imprisoned Parents, University of Ulster and Bambinisenzasbarre, 2011.

Covington, Stephanie y Bloom, Bárbara E., "Gendered justice: women in the criminal justice system", en Gendered Justice: Adressing Female Offenders, Carolina Academia Press, 2003.

Cunnighan, Ann, "Forgotten families. The impact of the imprisonment", en Family matters, n. ${ }^{\circ}$ 59, Winter 2001.

Crawford, Jackie, "Alternative sentencing necessary for female inmates with children”, en Corrections today, n. ${ }^{\circ}$ 65, tomo 3, junio 2003.

Dalley, Lanette, "Policy implications relating to inmate mothers and their children: will the past be prologue", en The prison journal, vol. 82, n. . 2, June 2002.

Dickie, D. Financial impact of imprisonment on families, Families outside 2013.

De la Rosa Cortina, "La nueva prisión atenuada domiciliaria ¿una alternativa a la prisión provisional ordinaria?”, en Diario La Ley, n. . 6148, 16 de diciembre de 2004.

Gudin Rodríguez, Cárcel electrónica versus prisión preventiva, en [http://www2. uned.es/dpto-derecho-politico/Gudin_Prision_Preventiva.pdf].

Herrero Bernabé, El derecho de gracia: indultos, tesis doctoral, unED, Madrid, 2012, en [http://e-spacio.uned.es/fez/eserv/tesisuned:Derecho-Iherrero/Documento.pdf]. 
Hoffmann, Heath; Byrd, Amy y Kightlinger, Alex, "Prison programs and services for incarcerated parents and their under age children: results from a National Survey of Correctional Facilities", en The Prison Journal, 90 (4) 397-416, 2010.

Jones, Adele y Wainaina-Wozna, Agnieszka, Children of prisoners. Interventions and mitigations to strengthen mental Health, University of Huddersfield, 2013.

Kinner, Alati, Najman y Williams, "Do paternal arrest and imprisonment lead to child behaviour problems and substance use? A longitudinal analysis", en Journal of Child Psychology and Psychiatriy, 48: 11 (2007).

Lerer, Tamar, Sentencing the family: recognizing the needs of dependent children in the Administration of the Criminal Justice System, 9 Nw. J. L. \& Soc. Pol'Y. 24 (2013) y disponible en [http://scholarlycommons.law.northwestern.edu/njlsp/vol9/iss1/2/].

Leverentz, Andrea M., The prisoner's dilema. How women negotiate competing narratives of reentry and desistance, 2014.

Llorca Ortega, La ley de indulto (Comentarios, jurisprudencia,formularios y notas para su reforma), Valencia, 1995.

Marshall, Kathleen, Not seen, not Heard, not guilty, the rights and status of the children of prisoners in Scotland, 2008.

Mazza, Carl, "And then the world fell apart: the children of incarcerated fathers", en Families in society, September-December, n. . 5/6, 2002.

McIvor, Gill; Trotter, Chris y Sheehan, Rosemary, "Women, resettlement and desistance", en Probation Journal, vol. 56 (4), 2009.

McNeil, Fergus en Gill Robinson (comp.), From vision to reality- Transforming Scotland's care of women in custody, Symposium report, 2015.

Minson, Shona, Mitigating motherhood. A study of the impact of motherhood on sentencing decisions in England and Wales, The Howard League for Penal Reform, 2014.

Moses, Marylin C., "Correlating incarcerated mothers, foster care and mother-child reunification”, en Corrections Today, n. ${ }^{\circ}$ 68, 2006, pp. 98-100.

Mumola, Incarcerated parents and their children, Bureau of Justice Statistics. Special Report, agosto, 2000. 
Murray, Joseph y Farrington, David, "The effects of parental imprisonment on children", en Tonry (ed.), Crime and Justice: A review of research, vol. 37, pp. 133-206, Chicago, IL: University of Chicago Press.

Myers, Barbara J.; Smarsh, Tina M.; Amlund-Hagan, Kristine y Kennon, Suzanne, "Children of incarcerated mothers", en Journal of Child and Family Studies, n. 8, pp. 11 a 25, 1999.

Navarro Villanueva, Carmen, El encarcelamiento femenino, Atelier, Barcelona, 2018.

Navarro Villanueva, Carmen, Ejecución de la pena privativa de libertad, Juruá, Porto, 2019.

Navarro Villanueva, Carmen, "Otras víctimas olvidadas: los menores cuya madre cumple condena de privación de libertad en un centro penitenciario", en AA. VV., La víctima menor de edad. Un estudio comparado Europa-América, Colex, Madrid, 2010.

Pacheco, Lecciones de derecho penal I, XXI.

Pillado González, Esther y Martínez Soto, Tamara, “Aplicación judicial de la suspensión de la ejecución de pena privativa de libertad. Una visión desde la justicia terapéutica", en Cachón Cadenas y Franco Arias (coords.), Derecho y proceso. Liber amicorum del profesor Francisco Ramos Méndez, vol. III, Atelier, Barcelona, 2018.

Racionero Carmona, Derecho penitenciario y privación de libertad. Una perspectiva judicial, Dykinson, Madrid, 1999.

Ramos Méndez, Enjuiciamiento criminal.Duodécima lectura constitucional, Atelier, Barcelona, 2016.

Reed, Kristiina, “Children of prisoners: 'orphans of justice'?”, Fam Law, January, 2014.

Robertson, Oliver, El impacto que el encarcelamiento de un(a) progenitor(a) tiene sobre sus hijos, Quaker ONU, abril, 2007.

Rodgers McCarthy, Belinda, "Inmate mothers: the problems of separation and integration", en Journal of Offender Counseling, Service and Rehabilitation, 4(3), 1980, pp. 199 a 208 (publicado on line 26 oct. 2008).

Rosenberg, Jennifer, Children need dads too: children with fathers in prison, Geneva, Quaker United Nations Office, 2009. 
Scharff-Smith, Peter y Gampell, Lucy (eds.), Children of imprisoned parents, The Danish Institute of Human Rights, European Network for Children of Imprisoned Parents, University of Ulster and Bambinisenzasbarre, 2011.

Shaw, "Imprisoned fathers and the orphans of justice", en Prisoners' Children: What are the issues, London, Routledge, 1992. 